\title{
Falls among Older Adults: A Community-Based Study in Rural Kerala, India
}

\author{
Rekha M. R. ${ }^{1,2}$, Mini G. K. ${ }^{1,3}$ \& Kutty V. R. ${ }^{1}$ \\ ${ }^{1}$ Achutha Menon Centre for Health Science Studies, Sree Chitra Tirunal Institute for Medical Sciences and \\ Technology, Trivandrum-695011, Kerala, India \\ ${ }^{2}$ State Health System Resource Centre Kerala (SHSRC-K), Thycaud, Trivandrum-695014, Kerala, India \\ 3 Centre for Public Health, Amrita Institute of Medical Sciences (AIMS), Amrita Vishwa Vidyapeetham \\ University, School of Medicine, Health Science Campus, Kochi-682041, Kerala, India \\ Correspondence: Dr G. K. Mini, Assistant Professor, Centre for Public Health, Amrita Institute of Medical \\ Sciences (AIMS), Amrita Vishwa Vidyapeetham University, School of Medicine, Health Science Campus, \\ Kochi-682041, Kerala, India. Tel: 91-94-9537-6825. E-mail: gkmini.2014@gmail.com; \\ minisureshkumar@yahoo.com
}

\author{
Received: August 1, 2017 Accepted: August 24, 2017 Online Published: September 13, 2017 \\ doi:10.5539/gjhs.v9n10p165 \\ URL: https://doi.org/10.5539/gjhs.v9n10p165
}

\begin{abstract}
The study examined the frequency and correlates of falls among community dwelling older adults ( $\geq 60$ years) in rural Kerala. We did a cross-sectional survey among 202 older adults using a pre-tested structured interview schedule. Falls in the previous year was reported by $27 \%$, among them, $20 \%$ fell more than once making a total of 74 falls. Injuries were reported among $58 \%$ of the fallers. Slips were the frequent cause of fall (25.6\%). Most falls happened outdoors (77\%). Age-sex adjusted results of multivariate logistic regression analysis showed that those having any morbidity, those with a history of previous falls and those with no formal education were more likely to fall compared to their counterparts. Awareness programs on the risk of falls for older adults and their close relatives are required in this population. Prevention strategies should focus on those having any morbidity, those with a history of previous falls and those without formal education.
\end{abstract}

Keywords: circumstances of falls, falls, India, older adults

\section{Introduction}

According to the World Health Organization (WHO), falls are the second leading cause of deaths due to accidental or unintentional injury in the world, and older adults ( $>=65$ years) suffer the greatest number of fatal falls (WHO, 2016). Injuries and deaths associated with falls are a major public health issue among older adults in countries with aging populations (Kannus et al., 1999). In developed countries, one in every three older adults aged 65 years and above fall every year (Tinetti, Speechley, \& Ginter, 1988; Kannus, Sievänen, Palvanen, Järvinen, \& Parkkari, 2005). Out of these falls, 5 to $30 \%$ result in major injuries that lead to disability, long-term confinement to bed and even death (Kannus et al., 1999; Ambrose, Paul, \& Hausdorff, 2013). However, data on falls among older adults from developing countries are limited (Johnson, 2006).

The clinical relevance of falls to an individual is directly correlated with negative outcomes, such as poor health and quality of life among older adults (Close, Lord, Menz, \& Sherrington, 2005). Once the circumstances of falls in older adults are known, preventive measures can be taken at various levels to avoid or reduce the number of falls. A previous study reported an inverse relationship between fall-related injuries and educational level (Li, Song, Yu, Zhou de, \& Zhang, 2013). One study, from the Indian state of Kerala, based on a small sample, reported that older adults living in institutions were more likely to fall compared to older adults living in homes (Johnson, 2003) indicating that family support was a positive factor in reducing falls. Carroll reported that injuries related to falls were among the 20 most expensive medical conditions (Carroll, Slattum, \& Cox, 2005), and the financial burden of related treatment increased with age (Burns, Stevens, \& Lee, 2016). Increased fall rate has been reported to reduce the length and quality of life (CEREPRI, 2012).

Among the 4,24,000 fall-related deaths that occurred globally in 2004, 22\% were from India (WHO, 2008). Falls constitute $63 \%$ of all injury deaths among adults aged 70 years and above in the country (Jagnoor et al., 2012). 
Falls among older persons are expected to increase along with the proportion of older adults in developing countries like India (WHO, 2008; Jagnoor, Keay, \& Ivers, 2013). In India, the second most populous country in the world after China, 8\% of the population were aged 60 years and above in 2011 (Registrar General of India, 2011). However, there are no comprehensive community-based studies on the prevalence of falls among older adults in India. Kerala is the most advanced Indian state in demographic and epidemiologic transition (Peters, Rao, \& Fryatt, 2003 ) with the highest proportion of older adults (12.6\%) in the country (Registrar General of India, 2011). It is regarded as a harbinger of India's future in terms of chronic non-communicable diseases (Thankappan et al., 2010). Considering the strong relationship between falls and mortality and morbidity, especially among older adults, and increased cost due to hospitalisation and nursing care at home, prevention of falls is extremely important. Data on fall-related injuries and circumstances leading to falls among older adults in Kerala are limited. One study comparing the frequency of falls between 82 community-living and 63 institutionalised older adults in the state was limited by sample size and selection (convenient) (Johnson, 2006). Therefore, we conducted this study to determine the frequency and correlates of falls among community-dwelling older adults aged 60 years and above in the rural setting of Kerala.

\section{Material and Methods}

\subsection{Study Design}

We conducted a cross-sectional survey among older adults (60 years and above) in rural Thiruvananthapuram, the capital district of Kerala. The human development index (HDI) of this district was similar to the average score of 0.773 in the state (Government of Kerala, 2006). Among the 73 grama panchayats (the smallest political administrative unit in Kerala with 15000-30000 population) in the Thiruvananthapuram district, Athiyannur grama panchayat was used for the present study because of the availability of details of older adults in this panchayat collected as part of an ongoing program of the host institution (Soman, 2014).

\subsection{Sampling}

Based on the prevalence of falls of $38 \%$ among older adults ( $>60$ years) in the Indian state of Karnataka (Dsouza, Shringapure, \& Karol, 2008), the sample size was estimated as 192 with $95 \%$ confidence. Anticipating a $10 \%$ loss to follow-up, the final sample size was fixed as 212 older adults. From the list of 3,111 older adults in this panchayat (Soman, 2014), we randomly selected 212 older adults. Based on the address from the list, we approached the houses of all 212 older adults and found that eight had died and two had migrated to other places. The remaining 202 older adults consented to participate in this study. With the help of trained community volunteers from the same locality, all the selected older adults were approached between November 2012 and February 2013 by one of the authors (RMR), a medical doctor trained in public health.

\subsection{Data Collection}

Using a pre-tested structured interview schedule, the participants were asked for the details on age, education, marital status, monthly income of the household, economic independence, morbidity status and the details of falls in the last 12 months. The presence of certain diseases, such as visual deficit, respiratory problems, cardiovascular diseases, hypertension, dyslipidaemia, diabetes mellitus and knee pain were also gathered by self-reports. The inclusion criteria were those aged 60 years and above and able to answer our questions on history of falls during the previous year. Those who were bedridden or could not report the details of fall were excluded from the study.

\subsection{Definition}

A fall was defined as an event which results in a person coming to rest inadvertently on the ground or floor or other lower level (WHO, 2016). Details on the circumstances and context of fall, injuries due to fall, medical care availed, the time taken to return to pre-morbid functional status and changes following the falls were elicited from those who reported falls.

\subsection{Data Analysis and Ethical Clearance}

Data were analysed using SPSS version 20 [SPSS Inc., Chicago, IL]. The level of significance was set as $p<0.05$. Multiple logistic regression analysis was used to determine the factors associated with falls. Ethical clearance for the study was obtained from the Institutional Ethics Committee of Sree Chitra Tirunal Institute for Medical Sciences and Technology, Trivandrum. Written informed consent was obtained from all the participants before the survey. Informed consent was provided by those who were able to sign the consent form, and for others, thumb impression was taken.

\section{Results}

The mean age (SD) of the participants was $69.5 \pm 7.2$ years (ranging from 60 to 99 years). Women constituted 54.5\% 
of the sample. More than half $(53.5 \%)$ were in the age group of 60 to 69 years, and $24.8 \%$ were not formally educated. Fifty-nine percent were currently married (men $82 \%$, women $40 \%$ ). Approximately nine percent of the older adults were living alone, $23 \%$ were living with their spouse, sibling or a relative, whereas $68 \%$ lived in joint families (where more than one family lives together). Twenty percent reported economic dependence (men $14 \%$, women $25 \%$ ) on others, and the average monthly household income was reported as INR 3689 (approximately USD 53). Family was the main source of support for older persons who were dependent and those independent older adults when they required any additional help. Socio-demographic characteristics of the sample by sex is presented in Table 1.

Table 1. Socio-demographic characteristics of the sample by sex

\begin{tabular}{|c|c|c|c|c|}
\hline Socio-demographic characteristics & & Males (92) & Females (110) & Total (202) \\
\hline \multirow[t]{2}{*}{ Age (in years) } & $60-69$ & $37(40.2)$ & $71(64.5)$ & $108(53.5)$ \\
\hline & $>=70$ & $55(59.8)$ & $39(35.5)$ & $94(46.5)$ \\
\hline \multirow[t]{5}{*}{ Education } & Illiterate & $9(9.8)$ & $19(17.3)$ & $28(13.9)$ \\
\hline & No formal education & $10(10.9)$ & $12(10.9)$ & $22(10.9)$ \\
\hline & Primary & $25(27.2)$ & $32(29.1)$ & $57(28.2)$ \\
\hline & Secondary & $41(44.5)$ & $42(38.2)$ & $83(41.1)$ \\
\hline & Higher secondary and above & $7(7.6)$ & $5(4.5)$ & $12(5.9)$ \\
\hline \multirow[t]{4}{*}{ Marital Status } & Currently Married & $75(81.5)$ & $44(40.0)$ & $119(58.8)$ \\
\hline & Never Married & $2(2.2)$ & $3(2.7)$ & $5(2.5)$ \\
\hline & Widowed & $14(15.2)$ & $56(50.9)$ & $70(34.7)$ \\
\hline & Separated & $1(1.1)$ & $7(6.4)$ & $8(4.0)$ \\
\hline \multirow[t]{2}{*}{ Monthly income } & $<5000$ INR & $71(77.2)$ & $101(91.8)$ & $172(85.1)$ \\
\hline & $\geq 5000 \mathrm{INR}$ & $21(22.8)$ & $9(8.2)$ & $30(14.9)$ \\
\hline \multirow[t]{2}{*}{ Economic Independence } & Dependent & $13(14.1)$ & $27(24.5)$ & $40(19.8)$ \\
\hline & Independent & 79 (85.9) & $83(75.5)$ & $162(80.2)$ \\
\hline
\end{tabular}

Fifty-four older adults reported at least one fall within a period of twelve months preceding the interview $(26.7 \%$; 95\% CI: 20.6-32.8). Of the fallers, 43 persons (79.6\%) fell once, seven persons (12.9\%) fell twice, two persons (3.7\%) fell three times, one person (1.9\%) fell five times and one person (1.9\%) fell six times. Thus, a total of 74 falls were reported in the reference period for those 54 persons. Among them, injuries were reported among 43 (58\%). Of the 43 injures, $72 \%$ sought medical attention. Of the seven fractures reported, three were hip fractures.

There was no significant difference in the proportion of falls between men and women (men: $26.1 \%$, women: $27.3 \%, p=0.98$ ) and among different age groups ( $\geq 70$ years: $21.3 \% ;<70$ years: $33 \%, p=0.09$ ). The proportion of injuries reported in different parts of the body is presented in Figure 1. Most of the falls happened during walking (61.1\%), followed by getting up from the cot or chair $(11.1 \%)$, around the barn or the well $(9.3 \%)$, on the way to toilet (7.4\%), standing (3.7\%), walking in the backyard (3.7\%), climbing stairs $(1.9 \%)$ and during bath (1.8\%). 


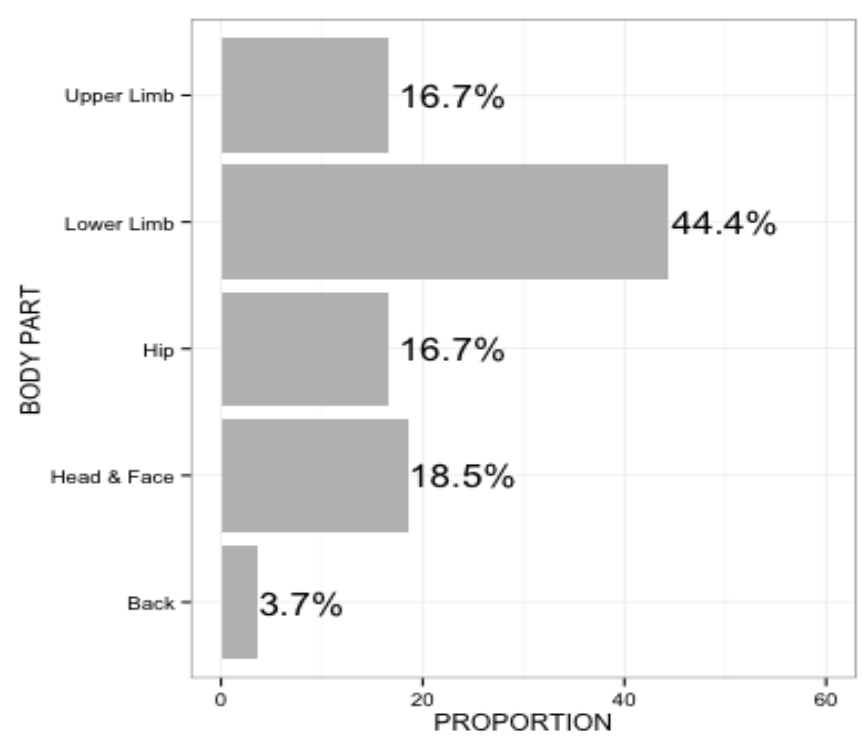

Figure 1. Proportion of injuries on different parts of the body

We collected the details of time of fall. Forty-three percent of the falls (32/74) happened during forenoon (6 am to $11: 59 \mathrm{am}), 40 \%(29 / 74)$ during afternoon (12 noon and 5:59 pm) and 17\% (13/74) at night (6 pm to 5:59 am).

We gathered details of the presumed cause of fall in all the 74 falls. We could not identify the cause of fall in three cases. Among the others, we classified the cause of fall into two categories: intrinsic and extrinsic. Fifty-two percent of the falls were intrinsic, and $48 \%$ had extrinsic causes. The intrinsic causes identified were fainting (48.7\%), losing balance while walking (40.5\%) and legs giving way $(10.8 \%)$. The extrinsic causes identified were slipping (55.9\%) and tripping (44.1\%).

Of the total fallers, $19 \%$ could not recover their functional status after the fall, $18 \%$ took more than six months to get well, $35 \%$ took less than a week to recover and the remaining $28 \%$ could resume their normal life immediately after the fall since there were no major injuries related to the fall.

Regarding physical, social and mental changes following the fall, half of the participants reported several changes after the fall. Of them, $56.7 \%$ reported fear of fall, $18.9 \%$ were depressed, $13.5 \%$ felt less confident in walking alone and $10.9 \%$ felt insecure after the fall.

The association of falls with different characteristics of the study participants is represented in Table 2. Lack of formal education, history of previous fall and having any morbidity were significantly associated with the prevalence of fall. Specific conditions, such as dyslipidaemia and knee pain were significantly associated with prevalence of fall. 
Table 2. Association of falls with background characteristics of older adults: Results of bivariate analysis

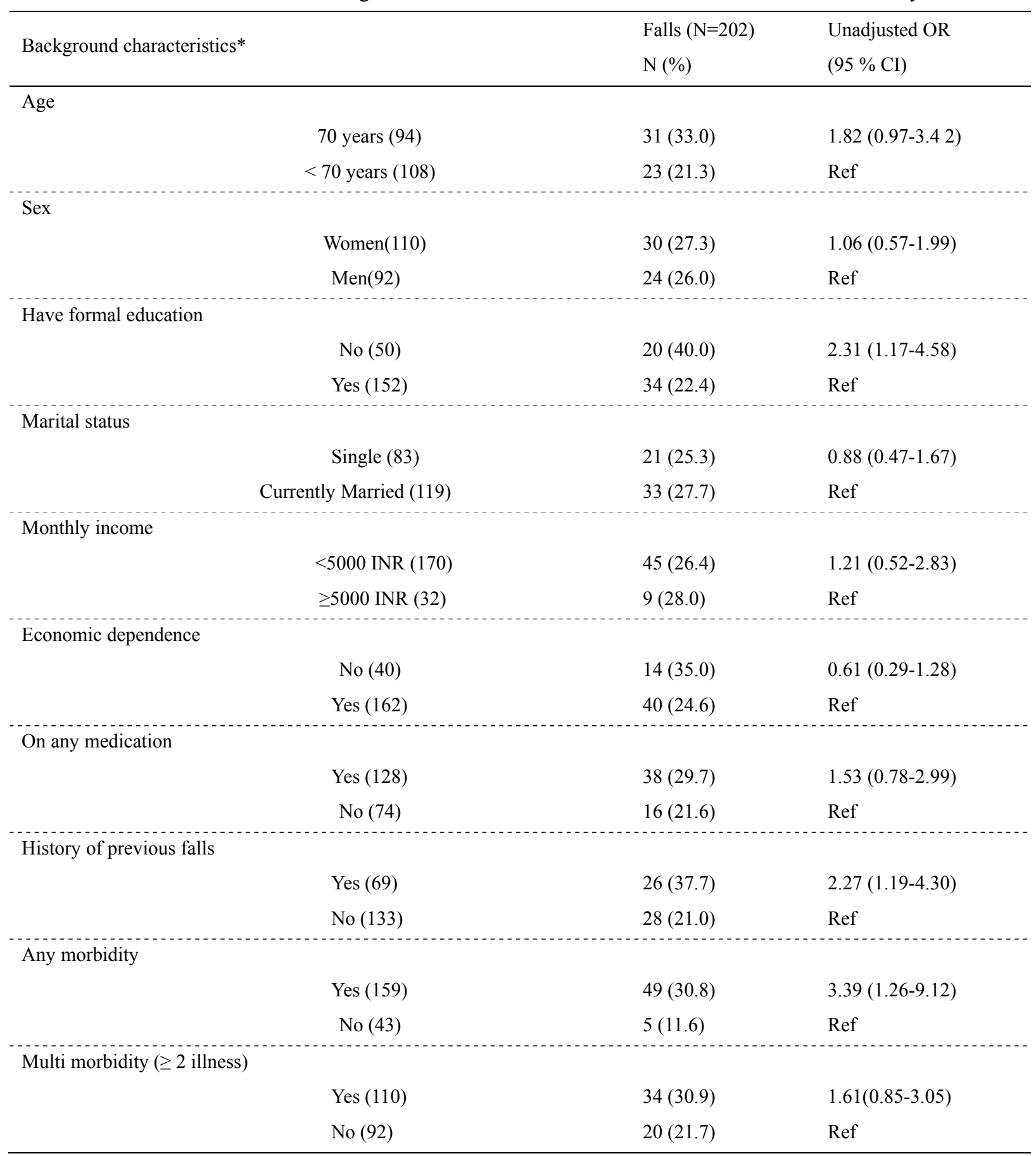

*The figures in brackets are the total sample in each category.

Age- and sex-adjusted results of multivariate logistic regression analysis (data not shown in tables) on correlates of fall showed that those having any morbidity (OR 3.45, 95\% CI 1.24-9.58), those with a history of previous falls (OR 2.26, \% CI 1.15-4.44) or those with no formal education (OR 2.12, CI 1.02-4.40) were more likely to fall compared to their counterparts.

\section{Discussion}

The prevalence of falls reported in the present study $(26.7 \%)$ was similar to that reported in other developed countries (Tinetti, Speechley \& Ginter, 1988; WHO, 2008; Prudham \& Evans, 1981). Prevalence of fall among older adults was reported as $23 \%$ in Nigeria and ranging from $21.6 \%$ to $34 \%$ in Latin American and Caribbean 
countries (Bekibele \& Gureje, 2010; Reyes-Ortiz, Al Snih \& Markides, 2005). A higher incidence rate of falls was reported in Sri Lanka (492 per 1000 person years) (Ranaweera, Fonseka, PattiyaArachchi \& Siribaddana, 2013) and a low prevalence in Pakistan (8.85 per 1000 person years) (Bachani, Ghaffar \& Hyder, 2011). An earlier finding from the state of Kerala, based on a convenient sample of older adult women, reported a higher prevalence of falls (45\%) among community-dwelling participants (Kannus, Sievänen, Palvanen, Järvinen \& Parkkari, 2005). Our study found no significant gender difference in the prevalence of falls in men and women, similar to the findings reported among older adults living in the community (WHO, 2016) and contrary to the findings that reported a lower prevalence of falls among men compared to women among older adults in Ecuador (US) (Orces, 2013). The present study found more injurious falls among women than men.

Our finding that $42 \%$ of falls resulted in serious injuries requiring medical attention is higher than that of $24 \%$ of serious falls reported earlier among older adults in Norway (Bergland \& Wyller, 2004). The proportion of fractures in our study, especially hip fractures, was also higher than that reported in earlier studies (Tinetti, Speechley \& Ginter, 1988; Ambrose, Paul \& Hausdorff, 2013; Mithal et al., 2013), which may be attributed to the higher prevalence of osteoporosis in India (Bergland \& Wyller, 2004).

The majority of the falls reported in the present study were outside the house, which was similar to that reported among older adults in Norway (Bergland \& Wyller, 2004). Falls occur most frequently during the day, while the older persons carried out their daily routines (Dsouza, Shringapure \& Karol, 2008). Similar to the findings of other studies (Tinetti, Speechley \& Ginter, 1988; Bleijlevens et al., 2010), our study also found that walking was the most common activity during falls. The intrinsic factors in combination with precipitating factors, such as slippery floors or tripping hazards, might have triggered the falls. This high proportion might be due to the general tendency of older persons to avoid climbing stairs, either to avoid falls or because of inability to climb stairs, and other activities involving physical strain.

Falls due to extrinsic factors were common. Slipping was the most frequent cause of falls as reported earlier (Tinetti, Speechley, \& Ginter, 1988; Dsouza, Shringapure, \& Karol, 2008; Blake et al., 1988). The trips and slips increase with increasing age as the tactic for not falling after a slip changes from "hip strategy' (fall avoidance through weight shifts at the hip) to "step strategy" (fall avoidance through a rapid step) (Rubenstein \& Josephson, 2006).

Older persons with no formal education had a significantly higher proportion of falls when compared to their counterparts. Lower education levels were also found to be an important risk factor for falls among older Chinese persons (Li, Song, Yu, Zhou de, \& Zhang, 2013). Lack of nutrition, information, access to healthcare and opportunities for improving behavioural factors associated with lower education might be the reason for this increased risk. The probability of falls was reported to be lower among older adults who had higher personal income (Trujillo, Puvanachandra \& Hyder, 2011). In our study, we did not find such a relationship. The association of lower nutrition levels of older adults with higher falls as reported earlier (Johnson, 2003) should be considered in planning services for older adults because of the higher prevalence of malnutrition reported among older adults in India (Mathew et al., 2016). The association of falls with the presence of chronic diseases was also well established (Wallace et al., 2002). Our study finding that falls were common among those with any morbidity, is similar to that reported in older adults in the United States of America (Wallace et al., 2002). The disease conditions along with the effects of medications might raise the risk for falls.

History of falls was identified as a risk factor for falls in a previous study (Ravindran \& Kutty, 2016). The proportion of recurrent fallers among total fallers $(20 \%)$ is of serious concern since serious fallers have more functional disabilities (Nevitt, Cummings, Kidd, \& Black, 1989). The results are comparable with the findings of Lord and Dayhew, who reported a $21.7 \%$ recurrence of falls in a prospective study in Sydney (Lord \& Dayhew, 2001).

The main strength of the study was that we collected data from a community-based sample of older adults selected randomly and administered the survey in their homes. One limitation of the study may be that the recall period of one year might have resulted in underreporting of minor falls (Cummings, Nevitt, \& Kidd, 1988) since people tend to forget minor falls but remember serious falls. The findings of the present study are not representative of older adults in Kerala because we did not include institutionalised older adults reported to have a higher risk of falls and related injuries (Luukinen, Koski, Honkanen, \& Kivela, 1995).

Falls constitute an important health problem among older adults in Kerala. Falls are multi-factorial, but a high proportion of them happen in and around the home. Due to Kerala's increasing aging population, fall rates are likely to increase and will create more burden at the individual, social and health system level. The increasing burden of non-communicable disease in the state of Kerala has captured much attention (Thankappan et al., 2010). 
However, most of the literature is focussed on heart disease, cancer and diabetes. Injuries, both intentional and unintentional, also add a heavy burden of morbidity to the aging population of the state. The findings of our study suggest that more research in this area is needed to plan prevention strategies and efforts to reduce falls and related injuries in order to improve the quality of life of older adults in the state.

\section{Conclusion}

In conclusion, our study provides data on falls and their correlates among older adults in the state of Kerala in India. Specifically, our findings highlight the injuries due to falls, circumstances of falls, times of falls and social, mental and physical changes due to falls. Although additional research is required for better understanding of the factors associated with falls among older adults in the state, our study emphasises the need to consider the presence of morbidity, lower levels of education and previous fall history when designing prevention strategies. Because the state has an increasing aging population with an increased life expectancy, fall rates are likely to increase and create more burden at the individual, social and health system level.

\section{Policy Recommendations}

Further studies to explore other risk factors are warranted to devise strategies for prevention of falls among older persons in Kerala as it is different from high income countries in the epidemiologic, demographic, developmental, political and cultural parameters. Studies on costing of falls are essential to highlight the economic impact of falls on an individual, family and the health system to appeal for policy attention. Caregivers of older adults can be given information and advice on prevention and management of falls, and an integrated approach to different intervention strategies for older adults can be developed. Health professionals can also help with the prevention and treatment of falls. Slipping was the most frequent cause for falls reported in the present study, which emphasises the need for structural modification during house building.

\section{Competing Interests Statement}

The authors declare that they has no competing or potential conflicts of interest.

\section{References}

Ambrose, A.F., Paul, G., \& Hausdorff, J. M. (2013). Risk factors for falls among older adults: a review of the literature. Maturitas, 75, 51-61. https://doi.org/10.1016/j.maturitas.2013.02.009

Bachani, A. M., Ghaffar, A., \& Hyder, A. A. (2011). Burden of fall injuries in Pakistan--analysis of the National Injury Survey of Pakistan. Eastern Mediterranean Health Journal, 17, 375-381.

Bekibele, C. O., \& Gureje, O. (2010). Fall Incidence in a Population of Elderly Persons in Nigeria. Gerontology, 56, 278-283. https://doi.org/10.1159/000236327

Bergland, A., \& Wyller, T. B. (2004). Risk factors for serious fall related injury in elderly women living at home. Injury Prevention, 10, 308-313. https://doi.org/10.1136/ip.2003.004721

Blake, A. J., Morgan, K, Bendall, M. J., Dallosso, H., Ebrahim, S. B., Arie, T. H.,...Bassey, E. J. (1988). Falls by elderly people at home: prevalence and associated factors. Age and Ageing, 17, 365-372. https://doi.org/10.1093/ageing/17.6.365

Bleijlevens, M. H., Diederiks, J. P., Hendriks, M. R., van Haastregt, J. C., Crebolder, H. F., \& van Eijk, J. T. (2010). Relationship between location and activity in injurious falls: an exploratory study. BMC Geriatrics, $0,40$. https://doi.org/10.1186/1471-2318-10-40

Burns, E. B., Stevens, J. A., \& Lee, R. L. (2016). The direct costs of fatal and non-fatal falls among older adults—United States. Journal of Safety Research, 58. https://doi.org/10.1016/j.jsr.2016.05.001

Carroll, N. V., Slattum, P. W., \& Cox, F. M. (2005). he cost of falls among the community-dwelling elderly. Journal of Managed Care Pharmacy, 11(4), 307-316. https://doi.org/10.18553/jmcp.2005.11.4.307

Center for Research and Prevention of Injuries-CEREPRI, Department of Hygiene \& Epidemiology, School of Medicine, Athens University. Fact sheet: Prevention of Falls among Elderly. Retrieved from https://www.injuryobservatory.net/wp-content/uploads/2012/08/Older-Guide-Prevention-of-Falls.pdf

Close, J. C., Lord, S. L, Menz, H. B., \& Sherrington, C. (2005). What is the role of falls? Best Practices \& Research. Clinical Rheumatology, 19, 913-935. https://doi.org/10.1016/j.berh.2005.06.002

Cummings, S. R., Nevitt, M. C., \& Kidd, S. (1988). Forgetting falls. The limited accuracy of recall of falls in the elderly. Journal of the American Geriatrics Society, 36, 613-616. https://doi.org/10.1111/j.1532-5415.1988.tb06155.x 
Dsouza, S. A., Shringapure, A., \& Karol, J. (2008). Circumstances and consequences of falls in Indian older adults. The Indian Journal of Occupational Therapy, 4, 3-11.

Government of Kerala. Human Development Report 2005. Thiruvananthapuram, Kerala: State Planning Board; 2006.

Jagnoor, J., Keay, L., \& Ivers, R. (2013). A slip and a trip? Falls in older people in Asia. Injury-International Journal of The Care of the Injured, 44, 701-702. https://doi.org/10.1016/j.injury.2013.03.009

Jagnoor, J., Suraweera, W., Keay, L., Ivers, R. Q., Thakur, J., Jha, P; \& Million Death Study Collaborators. (2012). Unintentional injury mortality in India, 2005: nationally representative mortality survey of 1.1 million homes. BMC Public Health, 12, 487. Retrieved from https://doi.org/10.1186/1471-2458-12-487

Johnson, C. S. (2003). The association between nutritional risk and falls among frail elderly. Journal of Nutrition Health \& Aging, 7(4), 247-250.

Johnson, S. J. (2006). Frequency and nature of falls among older women in India. Asia Pacific Journal of Public Health, 18, 56-61. https://doi.org/10.1177/10105395060180010901

Kannus, P., Parkkari, J., Koskinen, S., Niemi, S., Palvanen, M., Järvinen, M., \& Vuori, I. (1999). Fall-induced injuries and deaths among older adults. JAMA-Journal of the American Medical Association, 281, 1895-1899. https://doi.org/10.1001/jama.281.20.1895

Kannus, P., Sievänen, H., Palvanen, M., Järvinen, T., \& Parkkari, J. (2005) Prevention of falls and consequent injuries in elderly people. The Lancet, 366, 1885-1893. https://doi.org/10.1016/S0140-6736(05)67604-0

Li, Y. H., Song, G. X., Yu, Y., Zhou, de D., \& Zhang, H. W. (2013). Study on age and education level and their relationship with fall-related injuries in Shanghai, China. Biomedical and Environmental Sciences, 26, 79-86. http://dx. doi: 10.3967/0895-3988.2013.02.001.

Lord, S. R., \& Dayhew, J. (2001). Visual Risk Factors for Falls in Older People. Journal of the American Geriatrics Society, 49, 508-515. https://doi.org/10.1046/j.1532-5415.2001.49107.x

Luukinen, H., Koski, K., Honkanen, R., \& Kivela, S.L. (1995). Incidence of injury-causing falls among older adults by place of residence: a population-based study. Journal of the American Geriatrics Society, 43, 871-876. https://doi.org/10.1111/j.1532-5415.1995.tb05529.x

Mathew, A. C., Das, D., Sampath, S., Vijayakumar, M., Ramakrishnan, N., \& Ravishankar, S. L. (2016). Prevalence and correlates of malnutrition among elderly in an urban area in Coimbatore. Indian Journal of Public Health, 60, 112-117. https://doi.org/10.4103/0019-557X.184542

Mithal, A., Bonjour, J. P., Boonen, S., Burckhardt, P., Degens, H., El Hajj Fuleihan, G., ...IOF CSA Nutrition Working Group. (2013). Impact of nutrition on muscle mass, strength, and performance in older adults. Osteoporosis International, 24, 1555-1566. https://doi.org/10.1007/s00198-012-2236-y

Nevitt, M. C., Cummings, S. R., Kidd, S., \& Black, D. (1989). Risk factors for recurrent nonsyncopal falls. A prospective study. JAMA, 261, 2663-2668. https://doi.org/10.1001/jama.1989.03420180087036

Orces, C. H. (2013). Prevalence and Determinants of Falls among Older Adults in Ecuador: An Analysis of the SABE I Survey. Current Gerontology and Geriatrics Research, 495468. https://doi.org/10.1155/2013/495468

Peters, D. H., Rao, K. S., \& Fryatt, R. (2003). Lumping and splitting: the health policy agenda in India. Health Policy and Planning, 18, 249-260. https://doi.org/10.1093/heapol/czg031

Prudham, D., \& Evans, J. G. (1981). Factors associated with falls in the elderly: a community study. Age and Ageing, 10, 141-146. https://doi.org/10.1093/ageing/10.3.141

Ranaweera, A. D., Fonseka, P., PattiyaArachchi, A., \& Siribaddana, S.H. (2013). Incidence and risk factors of falls among the elderly in the district of Colombo. Ceylon Medical Journal, 58, 100-106. https://doi.org/10.4038/cmj.v58i3.5080

Ravindran, R. M., \& Kutty, V. R. (2016). Risk Factors for Fall-Related Injuries Leading to Hospitalization Among Community-Dwelling Older Persons A Hospital-Based Case-Control Study in Thiruvananthapuram, Kerala, India. Asia Pacific Journal of Public Health, 28, 70S-76S. https://doi.org/10.1177/1010539515611229

Registrar General of India. Census of India. Retrieved February 11, 2017 from http://www.censusindia.gov.in; 2011.

Reyes-Ortiz, C. A., Al Snih, S., \& Markides, K. S. (2005). Falls among elderly persons in Latin America and the 
Caribbean and among elderly Mexican-Americans. Pan American Journal of Public Health, 17, 362-369. https://doi.org/10.1590/S1020-49892005000500008

Rubenstein, L. Z., \& Josephson, K. R. (2006). Falls and Their Prevention in Elderly People: What Does the Evidence Show? Medical Clinics of North America, 90, 807-824. https://doi.org/10.1016/j.mcna.2006.05.013

Soman, B. (2014). Participatory GIS in action, a public health initiative from Kerala, India. ISPRS Journal of Photogrammetry and Remote Sensing, XL-8, 233-237. Retrieved from https://doi.org/10.5194/isprsarchives-XL-8-233-2014

Thankappan, K. R., Shah. B., Mathur, P., Sarma P. S., Srinivas, G., Mini, G.K., ...Vasan, R. S. (2010). Risk factor profile for chronic non-communicable diseases: results of a community-based study in Kerala, India. Indian Journal of Medical Research, 131, 53-63.

Tinetti, M. E., Speechley, M., \& Ginter, S. F. (1988). Risk Factors for Falls among Elderly Persons Living in the Community. The New England Journal of Medicine, 19, 1701-1707. https://doi.org/10.1056/NEJM198812293192604

Trujillo, A. J., Puvanachandra, P., \& Hyder, A. A. (2011). Individual income and falls among the elderly in Latin. America. Geriatrics \& Gerontology International, 11, 180-190. https://doi.org/10.1111/j.1447-0594.2010.00662.x

Wallace, C., Reiber, G. E., LeMaster, J., Smith, D. G., Sullivan, K., Hayes, S., \& Vath, C. (2002). Incidence of Falls, Risk Factors for Falls, and Fall-Related Fractures in Individuals with Diabetes and a Prior Foot Ulcer. Diabetes Care, 25, 1983-1986. https://doi.org/10.2337/diacare.25.11.1983

World Health Organization. (2008). WHO global report on falls prevention in older age. Geneva, Switzerland,2008.

World Health Organization. Retrieved May 18,2017 from http://www.who.int/mediacentre/factsheets/fs344/en/; 2016.

\section{Copyrights}

Copyright for this article is retained by the author(s), with first publication rights granted to the journal.

This is an open-access article distributed under the terms and conditions of the Creative Commons Attribution license (http://creativecommons.org/licenses/by/4.0/). 